\title{
Desenvolvimento de Í́ndice de Condição da Via (ICV) para Avaliação da Qualidade de Sistemas Cicloviário em Áreas Urbanas
}

\section{Development of Road Condition Index ( $\mathrm{RCI}$ ) for Quality Assessment of Cycle Systems in Urban Areas}

\author{
$\infty$ \\ Cristiano Farias Almeida \\ Universidade Federal de Goiás (UFG), Goiânia, Goiás, Brasil \\ cristianoalmeida@ufg.br \\ (iD) (9) \\ Luciana Joyce Hamer \\ lucianaj.hamer@gmail.com \\ Rafael Martins Lisboa \\ Universidade Federal de Goiás (UFG), Goiânia, Goiás, Brasil \\ rafael.recnov@gmail.com
}

Conselho Regional de Engenharia e Agronomia de Goiás (CREA-GO), Goiânia, Goiás, Brasil

\section{Resumo}

Esta pesquisa tem como objetivo desenvolver um índice, chamado Índice de Condição da Via (ICV), a ser usado para avaliar a qualidade de sistemas cicloviários a fim de auxiliar planejadores de sistemas de transportes na implantação e avaliação de sistemas cicloviários; além de aumentar a habilidade de gestores e profissionais na tomada de decisão, apresentando critérios para análises. O ICV foi desenvolvido baseado em constatações sobre o uso da bicicleta como modo de transporte sustentável, nos preceitos da psicologia ambiental e nos métodos de avaliação do nível de serviço aplicados ao transporte. Com isso, foram definidos oito (8) indicadores para compor o ICV, a saber: largura da via, velocidade, topografia, conflitos (estacionamentos, cruzamentos sem sinalização), fluxo de veículos, amenidades, pavimentação (qualidade) e uso do solo. Ao final, normatizou-se o ICV de forma análoga ao proposto por Eastman e jiang (2010) em que é possível classifica os segmentos em A, B ou C. Nesta escala se o valor apurado do ICV para o segmento estiver entre 0 até 0,33 é considerado ruim (C). De 0,33 até 0,67, o segmento apresenta uma boa situação (B). Quando o índice apresentar valor superior a 0,68, tem-se uma situação muito boa (A).

Palavras-chave: Sistema cicloviário. Índice de condição da via. Psicologia ambiental. Nível de serviço. 


\section{Abstract}

this research aims to develop an index, called Road Condition Index (RCI), to be used to assess the quality of cycle systems in order to assist transport system planners in the implementation and evaluation of cycle systems; in addition to increasing the ability of managers and professionals in decision making, presenting criteria for analysis. The RCI was developed based on findings about the use of bicycles as a sustainable mode of transport, the precepts of environmental psychology and the methods of assessing the level of service applied to transport. Thus, eight (8) indicators were defined to compose the RCI, namely: width of the road, speed, topography, conflicts (parking lots, intersections without signs), vehicle flow, amenities, pavement (quality) and land use. In the end, the RCI was standardized in a similar way to the one proposed by Eastman and Jiang (2010), which it is possible to classify the segments in $A, B$ or C. On this scale if the calculated value of the RCl for the segment is between 0 to 0.33 is considered bad (C). From 0.33 to 0.67 , the segment presents a good situation (B). When the index is higher than 0.68 , there is a very good situation (A).

Keywords: Cycle system. Road condition index. Environmental psychology. Service level.

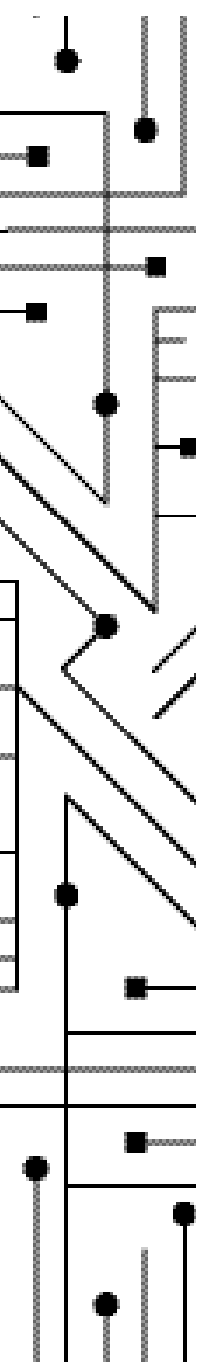




\section{Introdução}

Os problemas de mobilidade urbana atingem pontos alarmantes, e assistese a propostas políticas de intervenção em que o automóvel prevalece sobre os demais modos de deslocamentos, e com isso avançam os problemas que vão além da implantação de sua infraestrutura, como os aspectos ambientais e de saúde, decorrentes da má qualidade do ar; elevado número de acidentes de trânsito; congestionamentos; elevado índice de ocupação na área urbana em detrimento ao caminhar ou outro modo; falta de estacionamentos; alto consumo de energia e poluição sonora; segregação social, falta de acessibilidade e estresse.

A bicicleta apresenta-se como uma alternativa de mobilidade em que podese identificar benefícios pessoais, sociais ou ambientais, a saber: preservação dos espaços públicos, menores áreas de estacionamento, baixo nível de ruído, não uso de combustível fóssil, economicamente acessível à população (FHWA,1999).

Apesar de todas as características positivas relacionadas ao uso da bicicleta, as infraestruturas cicloviárias avançam de forma tímida. A falta de investimento e a escassez de diretrizes que incluam a bicicleta como uma alternativa viável para nortear as políticas de estímulo aos modos não motorizados são as principais razões deste quadro (KIRNER, 2006).

Estudos sobre o uso do comportamento e os fatores que influenciam a demanda cicloviária vem crescendo progressivamente, a exemplo dos trabalhos desenvolvidos por Pezzuto (2002) e Kirner (2006) no Brasil. Em outros países vários métodos foram propostos para avaliar o nível de serviço das ciclovias implantadas: Davis (1987), Epperson (1994), Sorton e Walsh (1994), Dixon (1996), Landis et. al. (1997), Hunter et. al. (1999), HCM (2000) e TRB (2000), cada uma com um objetivo específico, onde vários critérios foram abordados: acidentes com bicicletas, características das vias, sinalização, volume do tráfego, condições do pavimentos.

Entretanto, ainda pode ser considerado insuficiente o conhecimento, principalmente no Brasil, sobre o comportamento do usuário de bicicleta, a exemplo do estudo feito por Davis e Wicklatz (2001) os quais identificaram que as rotas usadas 
pelos ciclistas não passavam pelas ciclovias e ciclofaixas construídas, e um dos principais motivos apontados seria sua infraestrutura construída adjacente às vias de fluxo motorizado que estavam regularmente congestionadas.

Daí a importância do estudo comportamental mediante a definição e implantação dos sistemas cicloviários, visto que a maioria das pesquisas na área foca em temas relacionados com acidentes no trânsito, comportamento de segurança (uso de capacete) e a percepção da imagem da bicicleta.

Neste contexto, Gunther (2003) afirma que a mobilidade enquanto exploração é essencial para o desenvolvimento e bem estar humano, proporcionando affordance ${ }^{1}$ nos diferentes espaços físicos percorridos, suscitando comportamentos na sua interrelação. Para Everett e Watson (1987) é necessário ter entendimento psicológico do transporte como sendo a somatória dos comportamentos individuais; sendo assim, precisa ser considerado sob uma perspectiva humana juntamente com a parte tecnológica (DELABRIDA, 2004) em que busca-se unir o comportamento psicológico dos ciclistas e sua relação com o meio viário, a fim de contribuir para a introdução do modo cicloviário no transporte urbano e no planejamento de cidades.

Assim, este trabalho tem como objetivo desenvolver um índice para avaliar a qualidade de sistemas cicloviários a fim de auxiliar planejadores de sistemas de transportes na implantação e avaliação de sistemas cicloviários; além de aumentar a habilidade de gestores e profissionais na tomada de decisão, apresentando critérios para análises. Tal índice foi desenvolvido baseado em constatações sobre o uso da bicicleta como modo de transporte sustentável, nos preceitos da psicologia ambiental e nos métodos de avaliação do nível de serviço aplicados ao transporte.

\footnotetext{
1 affordance: conceito que pode ser definido como aquilo que o ambiente oferece ou proporciona para que as pessoas se comportem, de forma intuitiva ou baseados em experiências anteriores (LEWIN,1975). Affordances diz respeito ao que o ambiente oferta ao organismo que com ele interage sinergicamente (GUNTHER, 2003).
} 


\section{Fundamentação Teórica}

Nesta seção são apresentadas as bases teóricas que fundamentaram o desenvolvimento do Índice da Condição da Via (ICV) para avaliação da qualidade de sistemas cicloviários em áreas urbanas.

\section{A Bicicleta como Modo de Transporte Sustentável}

A elevada utilização de veículos individuais aumenta o fluxo veicular no sistema viário das cidades gerando problemas como: congestionamentos, acidentes, perda de espaço, poluição atmosférica, ruído, elevado consumo de energia. Tudo isso ocasiona efeitos adversos no ambiente natural urbano e degrada a qualidade de vida da população (RAMOS, 2008).

A bicicleta constitui um conjunto de modos de transportes sustentáveis que geram concomitantemente garantias de mobilidade e acessibilidade aos seus usuários, e que pode ser usado de forma democrática pelas sociedades nas cidades (RAMOS, 2008).

É perfeitamente perceptível que a melhoria na saúde, a melhoria da qualidade do ar e a dependência dos transportes que suam combustíveis fósseis são diretamente influenciados pelo número de viagens efetuadas por bicicleta, podendo estas serem incentivadas por meio de investimento, planejamento e fornecimento de infraestruturas (RAMOS, 2008).

Com o elevado uso da bicicleta como meio de deslocamento regular, alcançamse avanços em termos socioeconômicos e ambientais, a saber (Hamer, 2017):

- Evolução da saúde e segurança: trocando o veículo individual pela bicicleta, o que eleva a segurança da sociedade;

- Transporte ambientalmente amigável: redução dos impactos ambientais com a diminuição das emissões de material particulado para o ar;

- Diminuição da dependência em relação aos combustíveis fósseis: com o uso das bicicletas reduz-se o uso de veículos motorizados; 
- $\quad$ Equidade: avanço na interação e segurança da sociedade, ofertando simultaneamente menor custo e maior acessibilidade de transporte urbano;

- Eficiência: o uso de bicicletas requer menos espaço e menor investimento em infraestruturas que os veículos motorizados, podendo reduzir congestionamento.

A implantação da infraestrutura cicloviária no sistema de mobilidade das cidades afeta economicamente a área em seu entorno. A escala de vantagens que podem ser alcançados com o acréscimo desta distribuição modal a qual se agregam no contexto urbano, elevando o bem estar social, traz reorganização urbana devido à diminuição do fluxo veicular, combate à exclusão social e valorização dos empreendimentos locais (RAMOS, 2008).

\section{Nível de Serviço como Critério de Implantação e Avaliação de Sistemas Cicloviários}

Tentando melhorar o espaço urbano destinado à bicicleta, diversas metodologias chamadas como Níveis de Serviços (NS) foram desenvolvidas para avaliar a qualidade do sistema cicloviário em regiões urbanas centradas na infraestrutura (ver Hamer, 2017). Tais metodologias iniciam pela análise qualitativa considerando o conforto, a conveniência do condutor do veículo, a liberdade na escolha da velocidade e os obstáculos que surgem durante o trajeto, dentre elas a distância de outros automóveis e vias (TRB, 2000).

Alguns métodos criados expõem índices relacionados à convergência de vias e aspectos conectados ao comportamento espacial (Hamer, 2017). No Quadro 1, desenvolvido por Monteiro e Campos (2011), apresenta-se resumo dos métodos de análise dos ciclistas. 
Quadro 1 - Análises do nível de serviço

\begin{tabular}{|c|c|c|}
\hline $\begin{array}{c}\text { Autores/ } \\
\text { ano }\end{array}$ & Estudo & Variáveis de Segurança cicloviária \\
\hline $\begin{array}{l}\text { Epperson } \\
\text { e Davis } \\
\text { (1994) }\end{array}$ & $\begin{array}{l}\text { Avaliação do nível de serviço através } \\
\text { de um método que determina o } \\
\text { cálculo do Índice de Condição da Via } \\
\text { (ICV). }\end{array}$ & $\begin{array}{c}\text { Limite de velocidade } \\
\text { Largura da faixa externa } \\
\text { Volume de tráfego médio diário } \\
\text { Quantidade de faixas de tráfego } \\
\text { Qualidade do pavimento } \\
\end{array}$ \\
\hline $\begin{array}{l}\text { Sorton e } \\
\text { Walsh } \\
\text { (1994) }\end{array}$ & $\begin{array}{l}\text { Avaliação da qualidade das viagens } \\
\text { por bicicletas a partir da relação entre } \\
\text { as características das vias que o } \\
\text { ciclista utiliza e o stress a que este } \\
\text { está sujeito. } \\
\end{array}$ & $\begin{array}{c}\text { Volume de tráfego } \\
\text { Velocidade dos veículos automotores } \\
\text { Largura da Via }\end{array}$ \\
\hline $\begin{array}{l}\text { Botma } \\
(1995)\end{array}$ & $\begin{array}{l}\text { Análise da qualidade das vias para } \\
\text { bicicletas deve ser em relação aos } \\
\text { conflitos entre os próprios ciclistas. }\end{array}$ & Volume de bicicletas \\
\hline $\begin{array}{l}\text { Dixon } \\
(1996)\end{array}$ & $\begin{array}{l}\text { Sistema de pontuação para avaliar } \\
\text { corredores cicloviários. }\end{array}$ & $\begin{array}{c}\text { Conflitos na via } \\
\text { Diferencial de velocidade entre veículos motorizados e } \\
\text { bicicleta } \\
\text { Manutenção das vias }\end{array}$ \\
\hline $\begin{array}{l}\text { Landis et. } \\
\text { al (1997) }\end{array}$ & $\begin{array}{l}\text { Classificação das vias cicláveis, sob o } \\
\text { ponto de vista dos ciclistas. }\end{array}$ & $\begin{array}{l}\text { Volume de tráfego } \\
\text { Número de faixas } \\
\text { Limite de velocidade } \\
\text { Condição do pavimento } \\
\text { Largura média da faixa externa }\end{array}$ \\
\hline $\begin{array}{c}\mathrm{HCM} \\
(2000)\end{array}$ & $\begin{array}{c}\text { Análise da capacidade e o nível de } \\
\text { serviço das instalações para } \\
\text { bicicletas. }\end{array}$ & $\begin{array}{c}\text { Densidade de entradas para veículos } \\
\text { Diferença de velocidade entre bicicletas e automóveis }\end{array}$ \\
\hline $\begin{array}{l}\text { Monteiro e } \\
\text { Campos } \\
(2011)\end{array}$ & $\begin{array}{l}\text { Proposta de indicadores para } \\
\text { avaliação da qualidade dos espaços } \\
\text { para ciclistas. }\end{array}$ & $\begin{array}{c}\text { Travessias seguras por meio de sinalização ou passarelas } \\
\text { Distância segura do fluxo de veículos motorizados } \\
\text { Volume de veículos na via no caso de ciclofaixas } \\
\text { Quantidade de acidentes } \\
\text { Quantidade de entradas para veículos } \\
\text { Velocidade do fluxo dos veículos }\end{array}$ \\
\hline
\end{tabular}

Fonte: Monteiro e Campos (2011).

Os métodos propostos por Dixon (1996) e HCM (2000) são destacados por serem as bases teóricas usadas na construção do índice proposto neste artigo.

Dixon (1996) criou uma estrutura de contagem para avaliar o nível de serviço das passagens cicloviárias no município de Gainesville, no estado da Flórida, Estados Unidos. O modelo tinha o propósito de avaliar a alocação dos ciclistas em vias arteriais e coletoras, em áreas urbanas. Tal modelo apoiou-se no princípio de que há um grupo de variáveis que precisa existir em um sistema viário para atrair adeptos do nãotransporte.

Na metodologia de Dixon (1996) são considerados seis fatores de análise, a saber: facilidades para bicicletas, conflitos, distância de visibilidade não obstruída, melhorias das interseções para ciclismo, diferencial de velocidade entre veículos e 
bicicletas, nível de serviço motorizados, manutenção das vias e iniciativas específicas para melhorar o transporte cicloviário (Quadro 2).

Quadro 2 - Sistema de pontuação do Nível de Serviço do segmento analisado.

\begin{tabular}{|c|c|c|}
\hline Categoria & Critérios & Pontos \\
\hline \multirow{4}{*}{$\begin{array}{l}\text { Facilidades para bicicletas } \\
\quad(\text { Valor máximo }=10)\end{array}$} & Ciclofaixa - faixa externa $\leq 3,66 \mathrm{~m}$ & 0 \\
\hline & Ciclofaixa - faixa externa $3,67 \mathrm{~m}-4,27 \mathrm{~m}$ & 5 \\
\hline & Ciclofaixa - faixa externa $\geq 4,27 \mathrm{~m}$ & 6 \\
\hline & Ciclovia & 4 \\
\hline \multirow{6}{*}{$\begin{array}{c}\text { Conflitos } \\
(\text { Valor máximo }=4)\end{array}$} & Poucas entradas de garagem e cruzamentos & 1 \\
\hline & Ausência de barreiras & 0,5 \\
\hline & Ausência de estacionamento lateral & 1 \\
\hline & Presença de canteiros centrais & 0,5 \\
\hline & Distância de visibilidade não obstruída & 0,5 \\
\hline & Tratamento de interseções para o ciclismo & 0,5 \\
\hline \multirow{3}{*}{$\begin{array}{c}\text { Diferença de velocidades } \\
\text { entre bicicletas e veículos } \\
\text { motorizados } \\
(\text { Valor máximo }=2)\end{array}$} & $>48 \mathrm{~km} / \mathrm{h}$ & 0 \\
\hline & $33-48 \mathrm{~km} / \mathrm{h}$ & 1 \\
\hline & $24-32 \mathrm{~km} / \mathrm{h}$ & 2 \\
\hline \multirow{3}{*}{$\begin{array}{l}\text { Nível de serviço para } \\
\text { veículos motorizados } \\
(\text { Valor máximo }=2)\end{array}$} & $\mathrm{NS}=\mathrm{E}$ ou F (ou 6 ou mais faixas de tráfego) & 0 \\
\hline & $\mathrm{NS}=\mathrm{D}$ (e menos de 6 faixas de tráfego $)$ & 1 \\
\hline & $\mathrm{NS}=\mathrm{A}, \mathrm{B}$ ou $\mathrm{C}$ (e menos que 6 faixas de tráfego) & 2 \\
\hline \multirow{3}{*}{$\begin{array}{l}\text { Manutenção das vias } \\
(\text { Valor máximo = 2) }\end{array}$} & Problemas graves ou frequentes & -1 \\
\hline & Problemas pequenos e menos frequentes & 0 \\
\hline & Ausência de problemas & 2 \\
\hline \multirow{2}{*}{$\begin{array}{c}\text { Iniciativas voltadas ao } \\
\text { transporte cicloviário } \\
(\text { Valor máximo }=1)\end{array}$} & Sem iniciativas & 0 \\
\hline & Iniciativas existentes & 1 \\
\hline
\end{tabular}

Fonte: Dixon (1996).

Os segmentos são pontuados e classificados entre o Nível de Serviço "A" à "F", sendo: $(A)$ vias seguras e atrativas; $(B)$ adequadas para quaisquer ciclistas; (C) adequadas para maioria dos ciclistas; (D) adequada para ciclistas experientes; (E) requerer cuidados para ciclistas; $(F)$ inadequada.

Hamer (2017) descreve que a metodologia proposta pelo Highway Capacity Manual (TRB, 2000) pode ser usada para avaliar a capacidade e o nível de serviço de facilidades para bicicletas. A autora ainda descrever que o uso de tal metodologia 
permite identificar os efeitos dos pedestres, da sinalização de trânsito e da interação entre ciclistas no nível de serviço de uma instalação para bicicletas que é medido em termos de eventos ocorridos (encontros e ultrapassagens). O método proposto considera as instalações com fluxo ininterrupto de bicicletas que são vias separadas do tráfego veicular, sem interrupções, além dos pontos terminais, como as facilidades com fluxo interrompido, como por exemplo, ciclofaixas que passam por interseções semaforizadas ou não.

\section{Psicologia Ambiental e o Transporte}

Definir Psicologia Ambiental não é uma tarefa fácil. Fisher et. al. (1984) afirmam que descrevê-la é menos difícil do que defini-la. Para Heimstra e McFarling (1978) muito se fala sobre poluição do ar e da água, destruição do ambiente natural, ruídos, superpopulação; tópicos diversos que necessitam de contribuições investigativas de várias disciplinas e de profissionais que fazem interface com a arquitetura, o planejamento urbano e regional, a engenharia civil e sanitária, a geografia, a sociologia, a biologia, a administração de parques e a administração florestal, em que o ponto em comum se estabelece pelas relações existentes entre o homem e o ambiente físico.

Moser (1998) agrega o valor investigativo da psicologia ambiental referente ao comportamento do indivíduo com foco nas inter-relações entre o indivíduo e o ambiente físico/social, mediado pela percepção, avaliação e atitudes individuais em relação ao ambiente.

Para Everette Watson (1987), o transporte é um fator desafiador para a psicologia ambiental, aplicado ao dia a dia de nossas cidades, e pouco se tem explorado. Neste sentido, faz-se necessário ter um entendimento psicológico do transporte, afinal, todas as pessoas o utilizam de uma forma ou de outra, e é preciso considerar que o fenômeno do transporte é uma somatória dos comportamentos dos indivíduos nos contextos urbanos; sendo assim, precisa ser considerado dentro de uma perspectiva mais humana, do que de uma visão exclusivamente tecnológica. 
A Psicologia Ambiental pode contribuir por seu ângulo de estudo, já que estuda "a transação entre indivíduos e o seu ambiente físico". Nestas transações, indivíduos modificam o ambiente e seu comportamento e experiência são modificados pelo “ambiente" (GIFFORD, 1987).

É possível compreender como os indivíduos se relacionam com um determinado modo de transporte em um dado ambiente físico, e a dinâmica que se estabelece a partir daí: o impacto que o transporte terá sobre a vida das pessoas e como essas pessoas irão modificar o ambiente e se modificar a partir dessa relação. Segundo Hamer (2017), a relação de intervenção considera, portanto, três aspectos da Psicologia Ambiental: (I) espaço físico; (II) comportamento; e (III) a ligação recíproca entre (I) e (II). Nesse sentido, entende-se que:

I.Espaço físico é a acuidade dos ambientes físicos, e seus diversos sentidos (visão, audição, etc.), mas compila inúmeros estímulos concomitantemente (GUNTHER, 2003);

II. O comportamento e a conduta humana podem ser admitidos tanto individualmente quanto em grupo, a fim de que o ambiente individual não ocorra de forma separada, mas na companhia de outros, em uma conjunção conhecida como ambiente social (GUNTHER, 2003);

III. Ligação recíproca baseia-se nas associações bidirecionais e no efeito das pessoas sobre o ambiente e o do ambiente sobre as pessoas, mas também na atividade de retorno entre a conduta e experiência das pessoas no ambiente físico (GUNTHER, 2003).

\section{Variáveis Psicológicas da Mobilidade Urbana}

Entende-se a psicologia referindo-se a conduta e à experiência nas aptidões do espaço físico, por outro lado, a noção de conexão mútua é própria da tendência específica da psicologia ambiental (HEIMSTRA; MCFARLING, 1978). 
Porém, os três aspectos auxiliam mais áreas de estudo, todas elas potencialmente identificáveis pelos elementos: comportamento, espaço e reciprocidade; motivo pela qual requerem uma etiqueta inclusiva da psicologia ambiental no estudo da mobilidade urbana (GUNTHER, 2003).

Para Gunther (2003) “ambiente” reúne as várias formas do espaço físico, além de incluir os objetos que, por suas affordances, alteram a relação pessoa-espaço físico. Tamanho e grau de controle de espaço físico não são somente um fim em si mesmos, mas aspectos importantes para a qualidade de vida da pessoa. O grau de mobilidade afeta o acesso a: (a) bens materiais e ideias relevantes subjetiva e objetivamente, e (b) affordances do ambiente (Hamer, 2017).

Gunther (2003) incorpora o fundamento do espaço físico ao ambiente urbano por meio da mobilidade, e apresenta quatro conceitos do ambiente físico, protuberantes para a conduta e experiência: espaço pessoal, territorialidade, privacidade e densidade/ apinhamento (GUNTHER, 2003).

\section{Espaço Pessoal}

Conceito proposto por Sommer (1969), o espaço pessoal refere-se a uma área com limites invisíveis que cercam o corpo das pessoas, sendo um território portátil o qual reflete dois usos: o primeiro refere-se à zona carregada emocionalmente ao redor de cada pessoa; o segundo uso refere-se aos processos pelos quais as pessoas delimitam e personalizam os espaços que habitam.

Para Lee (1977), toda pessoa tem uma área espacial em torno de seu corpo, cujas fronteiras só existem "na mente" e onde qualquer intrusão por outros é indesejável. Vilaça (2008) complementa afirmando que as dimensões do espaço pessoal estão relacionadas com sua história de vida, as circunstâncias especiais das pessoas nas quais ele se situa. Já a percepção e o ajustamento à distância interpessoal, segundo afirmação de Stokols (1996), são muito influenciados pelas tradições e normas culturais. 
Gunther (2003) destaca que o espaço pessoal é abalado à medida que o deslocamento no território conduza a pessoa a convivência com o espaço pessoal de outro indivíduo. De igual forma, reciprocamente, aspectos de espaço pessoal de um e do outro podem facilitar ou reprimir a sua mobilidade.

O controle do espaço pessoal ocorre por meio da regulação da distância que o indivíduo mantém das demais pessoas e as necessidades de espaço pessoal revelam-se variadas. Hall (1966) distinguiu quatro zonas espaciais mais usadas em interação social: íntima $(0,50 \mathrm{~m})$, pessoal $(0,50-1,50 \mathrm{~m})$, social $(1,50-3,50)$ e pública (3,50-7,00m), as quais são influenciadas pelas diversas ações que se deseja realizar e têm como objetivo a proteção da intimidade e a segurança da ação.

\section{Territorialidade}

Gifford (1987) descreve territorialidade como sendo um bloco de ações adotadas por parte de um indivíduo ou grupo, baseado em controle identificado, tentado ou real sobre um espaço físico realístico, objeto ou ideia, que pode provocar ocupação habitual, defesa, personalização e demarcação.

Para Heimstra e McFarling (1978), a territorialidade é um outro aspecto do comportamento espacial humano, frequentemente difícil de separar da manutenção do espaço pessoal. Uma pessoa fixa um território usando características existentes de seu espaço ou pela sua alteração, estabelecendo marcações e limites.

Segundo Hamer (2017), os estudos sobre territorialidade buscam compreender as relações de domínio e defesa dos diferentes níveis de território, bem como relacionar conceitos de apego e identidade do lugar. O enfoque social apresenta como os espaços estão compreendidos por vínculos afetivos e cognitivos (status, identidade, estabilidade familiar) e funcionam de base para a identidade do detentor, buscando compreender as relações de apego e identidade do "lugar" (SOMMER, 1969). Além dessas atribuições sociais, o território ainda tem funções físicas de proteção e controle (PAIVA, 2013). 
Altman (1975) projetou três tipos de territórios: primários, secundários e terciários. Os primários estão conectados ao bem-estar e à sobrevivência, sendo visitados por extensos períodos de tempo e têm uma feição mais específica, como por exemplo: casa, quarto e mesa de trabalho. Os territórios secundários possuem transição inferior ao primário, apresentando tempo de permanência de nível médio (temporário e transitório), como restaurantes, clubes e escolas. Já os terciários são espaços públicos, mas que podem ser de prioridade de qualquer pessoa, como ruas, calçadas, e vagas de parqueamento.

\section{Privacidade}

Para Altman (1975, p. 18), privacidade é o "controle seletivo do acesso a si mesmo ou a seu grupo", sendo um conjunto aceitável de mecanismos reguladores, fortemente determinados por normas sociais (LEE, 1977).

A satisfação a respeito da privacidade depende da vontade ou não da pessoa de se relacionar com outras pessoas em uma dada situação. Isso ocorre porque, em locais e situações distintas, cada pessoa necessita de diversos níveis de privacidade (PAIVA, 2013). A apropriação do espaço e a materialização por meio de elementos construtivos como paredes, janelas, jardins e portas, definem a situação de privacidade, podendo ser controlados, mediante caráter de interesse pessoal (VILAÇA, 2008).

\section{Densidade ou apinhamento}

Densidade se refere a quantidade de pessoas por unidade de espaço, ou seja, a densidade é uma grandeza exata. Por outro lado, apinhamento diz respeito a uma condição psicológica que inclui estresse e a necessidade de se afastar de uma posição identificada pessoalmente como densa (BELL et al., 1996).

O conceito de "crowding", traduzido para o português como ajuntamento, apinhamento ou superpovoamento, corresponde a uma situação percebida como desconfortável, ocasionado pela invasão de seu espaço pessoal. Tais situações podem 
ser interpretadas como estressantes, determinando comportamentos adversos, onde o ambiente é percebido como fonte ameaçadora (TUAN, 1983).

Várias condições podem afetar as reações individuais aos graus distintos de densidade expostos, a saber: aspectos das pessoas e dos grupos, idade, gênero, propósito das relações, preferência das pessoas de estar no local lotado e motivos culturais (MORVAL, 2007).

O comportamento do indivíduo no ambiente pode sofrer impacto oriundo de inúmeros fatores, isso pode despertar reações contrárias como ansiedade, aflição e desejo de deixar tal ambiente. Essas reações dependem da forma como o indivíduo teve seu espaço acometido percebe essa situação e quais são desejos pessoais, experiências anteriores e pressões culturais (MORVAL, 2007).

\section{Implicações Relacionadas à Mobilidade e a Psicologia Ambiental}

Para Kohlsdorf (1996), a apreensão dos "lugares" apresentada se refere ao planejamento e ao desenho das áreas urbanas, e a importância dos profissionais que desenvolvem avaliações e projetos segundo senso de relevância técnica. Porém, as decisões tomadas produzirão espaços reais que são percebidos e ocupados por seus usuários, conforme a forma de conhecimento sensível de caráter conotativo. Estabelecer a correspondência entre captar as características dos níveis cognitivos são atributos que definem as receptivas qualidades morfológicas que devem se integrar à cultura e às expectativas do local.

Portanto, é desejável que este caminho suscite "a legibilidade e a imaginabilidade" apresentadas por Lynch (1997) por meio de elementos urbanos que tragam atratividade ao percurso, como atividades econômicas pouco impactantes e presença de arborização integrada à paisagem urbana como elemento de boa qualidade ambiental do trajeto.

Considerando o trabalho Estudos Pessoa - Ambiente desenvolvido por Gunther (2003), o autor descreve que a mobilidade, enquanto conduta real ou experiência 
passada, possibilita aproximação às affordances nos vários espaços físicos transcorridos. Assim, conclui-se que a mobilidade é o elo que permite a relação mútua entre pessoa e espaços físicos. A affordance apontadora da interação psicológica refere-se à relação de segurança do usuário de bicicleta com as características ambientais e físicas.

Assim, as quatro variáveis da psicologia ambiental que podem ser relacionadas ao uso da bicicleta conforme apresenta Paiva (2013) são: espaço físico pessoal, territorialidade, privacidade e densidade (apinhamento).

O controle do espaço pessoal se estabelece através de dimensões seguras ao trânsito de bicicletas nas vias, o espaço para o movimento (envelope dinâmico), é variável em função da velocidade de circulação e do declive. Quando o ciclista se desloca com baixa velocidade, ele tem tendência a desviar do movimento em linha reta. Velocidade igual ou superior a $10 \mathrm{~km} / \mathrm{h}$ é suficiente para manter uma circulação confortável e sem perder o equilíbrio. Velocidade de $10 \mathrm{~km} / \mathrm{h}$ a distância adicional será de $0,2 \mathrm{~m}$, e abaixo de $10 \mathrm{~km} / \mathrm{h}$ o desvio aumenta. Por exemplo, em torno de 6 $\mathrm{km} / \mathrm{h}$ o desvio é de $0,8 \mathrm{~m}$ (Figura 1). Uma velocidade elevada em descida obriga a necessidade de considerar largura adicional; já nas ultrapassagens dos ciclistas por veículos motorizados deverá considerar-se uma distância média de 1,5 m.

Figura 1 - Espaços referenciais de circulação para ciclistas.
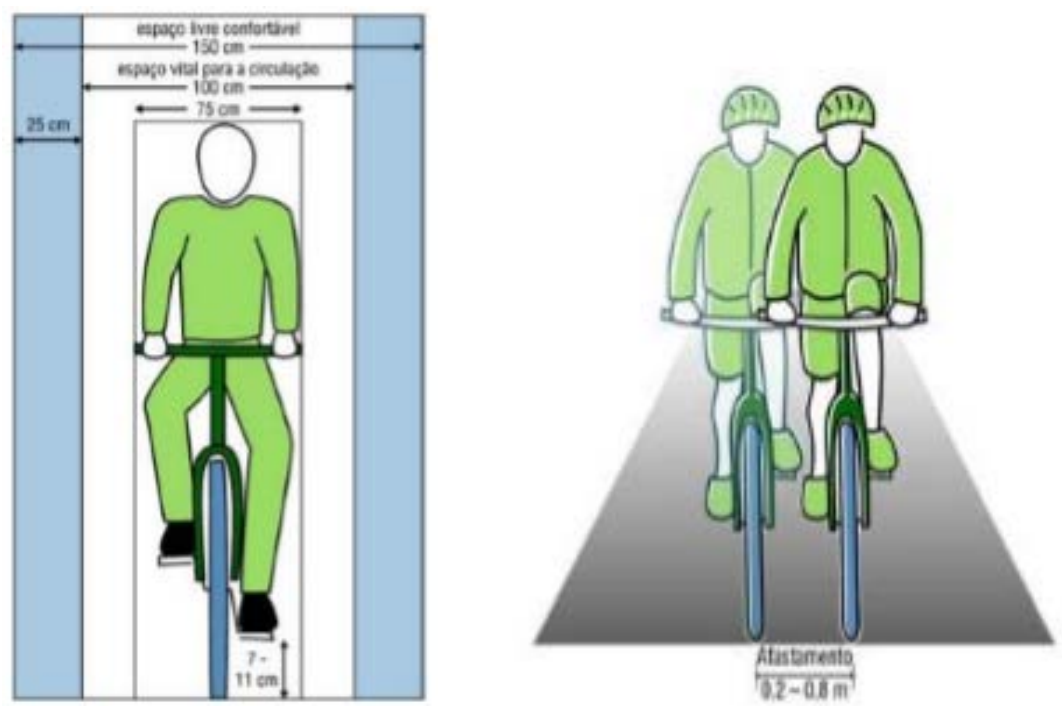

Fonte: Cycle Infrastructure Design (2010). 
O Código de Trânsito Brasileiro (BRASIL, 1997) estabelece as dimensões mínimas necessárias em projetos cicloviários. A distância lateral a ser mantida do veículo motorizado garante maior "privacidade" e segurança ao usuário da bicicleta. Para Paiva (2013), estas medidas são adotadas na maioria dos manuais de referência como o Aashato (1999), GEIPOT (2001), Brasil (2007), e Sustrans (2014).

Para Delabrida (2004), a privacidade consiste no controle do acesso de outras pessoas sobre o indivíduo e seu grupo nas vias de circulação. Para o usuário do automóvel, a situação viária é confortável se comparada à do ciclista, além de lhe conferir maior segurança, o ambiente do interior veicular lhe confere maior conforto.

A relação de densidade e apinhamento interfere no deslocamento por bicicleta, em que a quantidade de veículos em horários específicos pode elevar de forma significativa, causando congestionamentos.

Sockza (2005) caracteriza a situação de congestionamento do trânsito a situações de estresse, sendo esta uma dimensão psicológica presente no cotidiano urbano, onde verificou-se que $80 \%$ dos motoristas que viveram congestionamentos relataram agir com agressão, ansiedade e irritação. A sobredensidade na via diminui o espaço que o indivíduo tem para se deslocar e chegar ao seu destino.

Paiva (2013) relacionou o nível de serviço do manual HCM (2000) com as categorias do comportamento espacial. O manual HCM (2000) considera o conforto e a conveniência do motorista mediante a velocidade do veículo e as impedâncias durante a mudança de faixa e a distância entre os veículos nas vias. O Nível de Serviço (NS) de uma rodovia varia de "A" à "F". No nível "A", a via encontra-se desobstruída, podendo o condutor adotar a velocidade limite da via. À medida que o volume de tráfego aumenta, o NS diminui até atingir seu nível de saturação, "F". A Figura 2 representa o espaço pessoal ocupado por cada indivíduo na situação de pedestre e a regulação de distâncias mantidas entre os usuários na via considerada, onde as linhas sobrepostas representam a invasão do espaço pessoal. 
Figura 2 - Representação do espaço pessoal ocupado por pedestre.

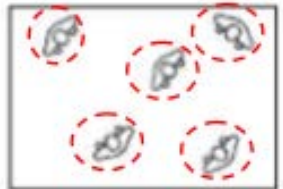

(a) Nível de Serviço A

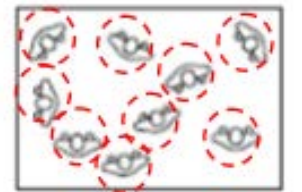

(b) Nível de Serviço C

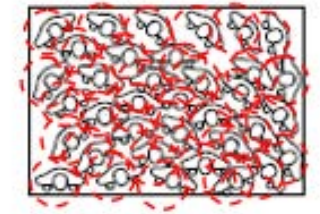

(c) Nível de Serviço F Fonte: TRB (2000) adaptado apud Paiva (2013).

A Figura 3 apresenta o espaço pessoal de automóveis de forma semelhante como foi apresentado o espaço pessoal do pedestre conforme Paiva (2013).

Figura 3 - Representação do espaço pessoal ocupado por pedestre.

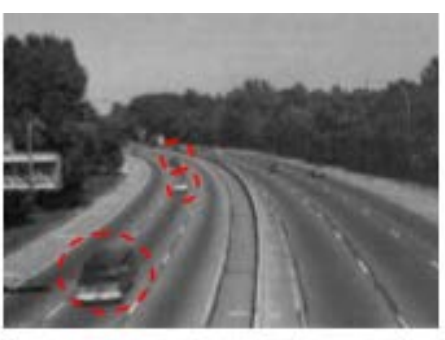

(a) Nível de Serviço A

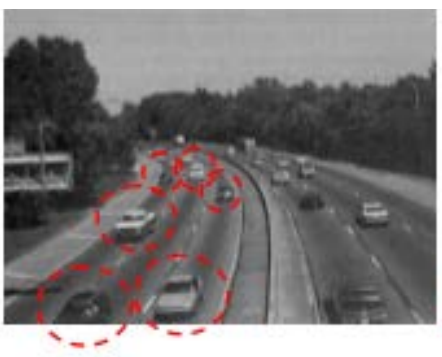

(b) Nível de Serviço C

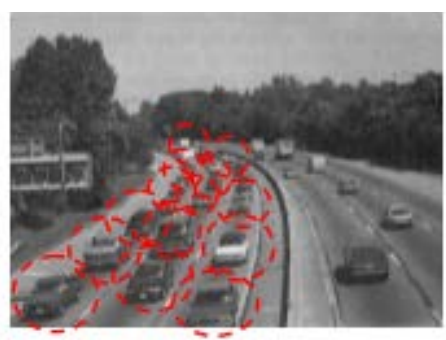

(c) Nível de Serviço F Fonte: TRB (2000) adaptado apud Paiva (2013).

Ambientes com grande aglomeração de pessoas (situação NS "F") podem ser vistos como estressantes. A relação também é estabelecida quanto aos usuários de bicicleta, por ser um veículo que expõe o usuário a riscos de colisão de forma direta (ver Figura 4). Outro fator considerado é a velocidade veicular e sua força aerodinâmica, as quais podem atingir o usuário de bicicleta, influenciando a sensação de invasão do espaço pessoal e o apinhamento dos usuários.

Figura 4 - Representação do espaço pessoal do ciclista em situação de adensamento.
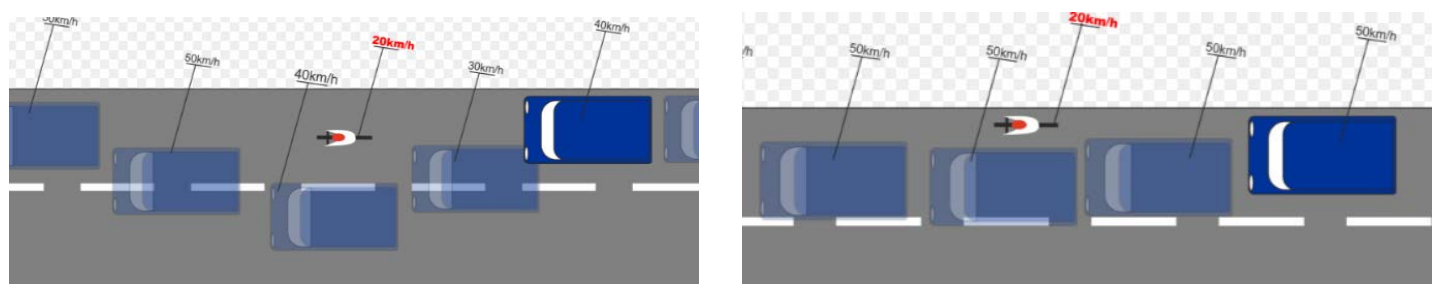

Fonte: Paiva (2013). 
Fundamentado nas premissas vistas anteriormente, Paiva (2013) procurou sumarizar os fatores que interferem a conduta da pessoa considerando as quatro categorias do comportamento espacial, segundo identificado no Quadro 3.

Quadro 3 - Fatores que influenciam nas categorias do comportamento espacial.

\begin{tabular}{|c|c|}
\hline Categorias & Influenciada por \\
\hline $\begin{array}{c}\text { Privacidade } \\
\text { (Controle do acesso de outras } \\
\text { pessoas ao ciclista) }\end{array}$ & $\begin{array}{c}\text { Interesse do ser humano em interagir com ouras pessoas, } \\
\text { Gênero, Personalidade, Condições pessoais do indivíduo e } \\
\text { Normas estabelecidas pela sociedade. }\end{array}$ \\
$\begin{array}{c}\text { Densidade - Apinhamento } \\
\text { (Quantidade de pessoas em um } \\
\text { ambiente) }\end{array}$ & $\begin{array}{c}\text { Número de pessoas em um determinando ambiente, Culturais, } \\
\text { Gênero, Proximidade de pessoas estranhas, Estresse e } \\
\text { motivação que fazem um ciclista deixar um determinado local } \\
\text { em função da quantidade de pessoas em um ambiente. }\end{array}$ \\
\hline $\begin{array}{c}\text { Territorialidade } \\
\text { (Atitudes dos ciclistas que têm por } \\
\text { objetivo demarcar o espaço físico } \\
\text { e organizar interaços) }\end{array}$ & $\begin{array}{c}\text { Sentimento de posse exclusividade de uso, Status/Poder, } \\
\text { Culturais e Dificuldade de controlar espaços. }\end{array}$ \\
\hline $\begin{array}{c}\text { Apreensão do espaço } \\
\text { (Capacidade de trazer ao espaço } \\
\text { legibilidade e imaginabilidade) }\end{array}$ & $\begin{array}{c}\text { Sentimento de posse e exclusividade de uso, Status/Poder, } \\
\text { Culturais e Dificuldade de controlar espaços. }\end{array}$ \\
\hline
\end{tabular}

Fonte: Paiva (2013).

\section{Desenvolvimento do Índice de Condições da Via (ICV) para Avaliação da Qualidade de Sistemas Cicloviários}

Nesta seção é desenvolvido o Índice de Condições da Via (ICV), a partir da etapas expressas como segue:

- Etapa I: Seleção dos indicadores

- Etapa II: Quantificação dos indicadores

o Hierarquização e mensuração de indicadores

o Seleção de entrevistados

o Aplicação da matriz junto aos entrevistados

o Definição de índices avaliativos

- Etapa III: Definição de ferramenta para avaliação do Índice de Condições da Via (ICV) 


\section{Etapa I: Seleção dos Indicadores}

$\mathrm{Na}$ primeira etapa foram selecionados dentre os indicadores referenciais apresentados na fundamentação teórica deste trabalho, em que se buscou-se a mensuração validada pelos ciclistas e profissionais da área técnica, apresentada pelo Método de Análise Hierárquica (MAH). Para cada item foram estabelecidos parâmetros em diferentes escalas de valores - respeitando o peso de cada referencial, conforme a abordagem da Psicologia Ambiental (GUNTHER, 2003) e os parâmetros geométricos para ciclovias.

Destaca-se o trabalho de Monteiro e Campos (2011) que sintetiza variáveis apresentadas pelos métodos de análises dos Níveis de Serviço, uma vez que Hamer e Almeida (2016) agregaram a estes critérios as categorias de comportamento espacial do ciclista, estudadas pela Psicologia Ambiental (Quadro 4).

Considerando a afirmação de Gunther (2003) que a mobilidade, enquanto comportamento, proporciona acesso às affordances nos diferentes espaços físicos percorridos, Hamer e Almeida (2016c) apresentaram indicadores para espaços de ciclistas baseados na interface de "segurança" do usuário de bicicleta, os quais estão apresentados no Quadro 5.

As variáveis apresentadas na avaliação dos níveis de serviço estão relacionados com as condições percebidas pelos ciclistas junto à Psicologia Ambiental em relação a conflitos e segurança, quanto às condições de infraestrutura e operação viária (HAMER e ALMEIDA, 2016c). 
Quadro 4 - Avaliações do nível de serviço e os critérios da Psicologia Ambiental.

\begin{tabular}{|c|c|c|c|c|}
\hline \multirow{2}{*}{$\begin{array}{l}\text { Metodologia } \\
\text { (Objetivo) }\end{array}$} & \multirow[b]{2}{*}{ Variáveis } & \multicolumn{2}{|c|}{ Privacidade } & \multirow[b]{2}{*}{ Territorialidade } \\
\hline & & $\begin{array}{l}\text { Espaço } \\
\text { Pessoal }\end{array}$ & Apinhamento & \\
\hline \multirow{5}{*}{$\begin{array}{c}\text { Epperson (1994) e Davis } \\
\text { (1987) }\end{array}$} & $\begin{array}{l}\text { Volume tráfego/ média } \\
\text { diária }\end{array}$ & & $x$ & \\
\hline & Número de Faixas & & $x$ & \\
\hline & Limite de velocidade & $x$ & & \\
\hline & Condições do pavimento & $x$ & & \\
\hline & $\begin{array}{c}\text { Fat. Localiz, estac, } \\
\text { declividade e intersecções }\end{array}$ & & & $x$ \\
\hline \multirow{3}{*}{$\begin{array}{l}\text { Sorton e Wash (1994) } \\
\text { Nivel de stress, hora de } \\
\text { pico }\end{array}$} & Volume do tráfego & $x$ & & \\
\hline & Vel. veículos automotores & & $x$ & \\
\hline & Largura da via & & $x$ & \\
\hline \multirow{6}{*}{$\begin{array}{l}\text { Dixon (1996) } \\
\text { Avaliar a acomodação } \\
\text { dos ciclistas em } \\
\text { corredores de vias } \\
\text { arteriais e coletoras }\end{array}$} & Infraestrutura & & & $x$ \\
\hline & $\begin{array}{c}\text { Conflitos/estacionamentos } \\
\text {-inserções }\end{array}$ & & & $x$ \\
\hline & $\begin{array}{c}\text { Diferencial de velocidade } \\
\text { entre veiculos }\end{array}$ & & $x$ & \\
\hline & $\begin{array}{l}\text { NS dos veículos } \\
\text { motorizados / sinalização }\end{array}$ & & & $x$ \\
\hline & Manutenção das vias & $x$ & & \\
\hline & $\begin{array}{l}\text { Prog. especificos melhor } \\
\text { transp. cicloviário }\end{array}$ & & & $x$ \\
\hline \multirow{6}{*}{$\begin{array}{c}\text { Landis et. al. (1997) } \\
\text { Avaliar nível de serviço } \\
\text { de bicicleta sob ponto de } \\
\text { vista do ciclista }\end{array}$} & $\begin{array}{l}\text { Volume tráfego média } \\
\text { diária }\end{array}$ & & $\mathrm{x}$ & \\
\hline & Número de Faixas & & $x$ & \\
\hline & Limite de velocidade & $x$ & & \\
\hline & $\begin{array}{c}\text { Porcentagem de veículos } \\
\text { pesados }\end{array}$ & & $x$ & \\
\hline & $\begin{array}{l}\text { Número de acessos } \\
\text { veiculares não } \\
\text { controlados }\end{array}$ & & & $x$ \\
\hline & Condição do pavimento & $x$ & & \\
\hline \multirow{3}{*}{$\begin{array}{c}\text { HCM (TRB, 2000) } \\
\text { Avaliar capacidade e o } \\
\text { NS através da } \\
\text { infraestrutura bicicleta }\end{array}$} & Fluxo/volume tráfego & & $x$ & \\
\hline & Velocidade & $x$ & & \\
\hline & $\begin{array}{c}\text { Diferença de velocidade } \\
\text { bicicleta } x \text { automóvel }\end{array}$ & $x$ & & \\
\hline
\end{tabular}

Fonte: Monteiro e Campos (2011) adaptada por Hamer e Almeida (2016). 
Quadro 5 - Propostas de variáveis para análise de espaços para ciclistas.

\begin{tabular}{|c|c|}
\hline \multirow{2}{*}{ Indicadores } & Variáveis \\
\hline & Espaço pessoal e apinhamento \\
\hline \multirow{7}{*}{ Percepção de seguridade /Mobilidade } & Presença de carros pesados \\
\hline & Presença de ciclovia ou ciclo faixa \\
\hline & Volume de veículos / ciclistas \\
\hline & Velocidade do fluxo viário \\
\hline & Largura da via ou ciclovia \\
\hline & Interseções e travessias \\
\hline & Distância "segura" dos veículos motorizados \\
\hline \multirow[b]{3}{*}{$\begin{array}{l}\text { Percepção de } \\
\text { Seguridade/Localização }\end{array}$} & Territorialidade \\
\hline & Densidade de ocupação da área \\
\hline & $\begin{array}{l}\text { Uso do solo (comércio, lazer, trabalho) } \\
\text { Segurança publica }\end{array}$ \\
\hline \multirow{6}{*}{ Segurança viária/Conforto } & Infraestrutura para bicicletas \\
\hline & Desnivel do terreno \\
\hline & Visibilidade no traçado e cruzamentos \\
\hline & Regularidade do pavimento \\
\hline & Estacionamento e inserções \\
\hline & Sinalização, Arborização, lluminação \\
\hline
\end{tabular}

Fonte: Hamer e Almeida (2016c).

Com isso, foram definidos 8 indicadores para compor o Índice de Condição da Via (ICV), sendo eles: largura da via, velocidade, topografia, conflitos (estacionamentos, cruzamentos sem sinalização), fluxo de veículos, amenidades, pavimentação (qualidade) e uso do solo.

\section{Mensuração de Indicadores para a Elaboração do Índice de Condição da Via}

Esta etapa é constituída pelas seguintes atividades: hierarquização e mensuração de indicadores, seleção de entrevistados, aplicação da matriz junto aos entrevistados e definição dos índices avaliativos, as quais serão descritas a seguir.

Hierarquização e Mensuração de Indicadores 
Com o intuito de hierarquizar e mensurar os indicadores avaliativos do nível de condições da via, foi realizada pesquisa com usuários de bicicletas e profissionais da área técnica. Neste caso, foi aplicado o Método de Análise Hierarquica (MAH) desenvolvido por Saaty (1991).

$\mathrm{O} \mathrm{MAH}$ permite julgamentos qualitativos e quantitativos de forma simples, pois estabelece relações hierárquicas considerando os diversos elementos a serem analisados e julgando-os segundo uma escala própria de valores, baseada no princípio de que a experiência e a percepção do analista poderão ser mensurados no processo de tomada de decisão. Este processo matemático visa representar a mente humana por meio de comparações paritárias sucessivas entre os diversos elementos que constituem a estrutura de análise (SOARES, 2006). Segundo Costa (2002) o método é baseado em três princípios:

- Construção de Hierarquias: o problema é estruturado em níveis hierárquicos o que facilita melhor compreensão e avaliação do mesmo. Para a aplicação desta metodologia é necessário que tanto os critérios quanto as alternativas possam ser estruturadas de forma hierárquica, sendo que no primeiro nível corresponda ao propósito geral do problema, o segundo aos critérios e o terceiro as alternativas.

- Definição de Prioridades: fundamenta-se na habilidade do ser humano de perceber a relação entre as coisas que se observa, comparando-as pelo julgamento da intensidade de sua preferência de um elemento sobre o outro de forma paritária (par a par), compondo uma matriz de julgamento com o uso de escalas apresentadas em escala numérica onde tem-se: 1 (igual importância), 3 (moderada importância), 5 (forte importância), 7 (importância muito forte) e 9 (extrema importância ) de um elemento sobre o outro. A quantidade de julgamentos necessários para a construção de uma matriz de julgamentos genérica $A$ é $n(n-1) / 2$, em que $n$ é o número de elementos pertencentes a esta matriz. Os elementos de A são definidos pelas seguintes condições: 
$A=\left[\begin{array}{cccc}1 & a_{12} & \cdots & a_{1 n} \\ 1 / a_{21} & 1 & \cdots & a_{2 n} \\ \vdots & \vdots & \cdots & \vdots \\ 1 / a_{n 1} & 1 / a_{n 2} & \cdots & 1\end{array}\right]$, onde:

Onde busca-se a normalização das matrizes de julgamento, o cálculo das prioridades médias e o cálculo das prioridade globais.

- Consistência Lógica: consiste em estabelecer relações de forma coerente, tal que estas se relacionem bem entre si e suas relações apresentem consistência (SAATY, 2001). Assim, o MAH se propõe a calcular a Razão de Consistência dos julgamentos, a qual é denotada por $R C=I C / I R$, onde IR é o Índice de Consistência Randômico obtido para uma matriz recíproca de ordem $n$, com elementos não-negativos e gerada randomicamente. $O$ Índice de Consistência $(I C)$ é dado por $I C=(\lambda$ máx $-n) /(n-1)$, onde $\lambda$ máx é o maior autovalor da matriz de julgamentos. Segundo Saaty (2001) a condição de consistência dos julgamentos é $R C \leq 0,10$. Valores superiores a este indicam falha na avaliação entre os pares ou na estruturação do problema (TREVIZANO e FREITAS, 2005).

\section{Seleção de Entrevistados}

Para Saaty (1991) o processo decisório proposto pelo método de Análise Hierárquica é realizado pelos tomadores de decisão (ou decisores) e analistas de decisão, não possuindo aspectos específicos dentro do MAH.

Considerando que a pesquisa busca apreender as condições percebidas do ambiente viário urbano pelo ciclista nas suas viagens pendulares e sua relação com o ambiente construído, entende-se que as intervenções viárias são realizadas por profissionais especialistas da área técnica em transportes. Assim, adotou-se o número de 10 entrevistados entre ciclistas e especialistas. 
Aseleção dos seis (6) ciclistas entrevistados pautou-se na busca da identificação do tempo de uso da bicicleta, de forma voluntária, em que buscou-se obter parâmetros comportamentais diferenciados, separando-os em dois grupos: com mais de três anos de experiência e com menos de três anos de experiência no uso da bicicleta para viagens regulares, totalizando seis ciclistas.

Para selecionar os quatro (4) profissionais a serem entrevistados, buscou-se adotar o critério da homogeneidade de formação de especialistas em transportes (mestres e doutores) que residiram e/ou realizaram trabalhos no setor de transportes na área objeto de estudo do caso, a cidade de Goiânia.

\section{Aplicação da Matriz Junto aos Entrevistados}

Para a aplicação da matriz junto aos entrevistados, realizou-se uma exposição de definições e conceitos, assim como instrução para seu preenchimento. Tal conteúdo foi encaminhado antecipadamente por e-mail aos entrevistados, mas o seu preenchimento ocorreu durante a entrevista.

Os indicadores propostos tiveram como referência o item 3.1, a saber: largura da via, velocidade, topografia, conflitos, amenidades, pavimentação e uso do solo. Assim, obtiveram-se as prioridades médias de cada entrevistador, validada seu grau de inconsistência da matriz $<0,1$.

\section{Definição de Índices Avaliativos}

Para a definição dos índices avaliativos foi necessário fazer a tabulação de todas as respostas dos entrevistados referentes aos oito indicadores analisados, juntamente com o índice de consistência (IC) de cada questionário. Assim, obteve-se a média aritmética dos indicadores, mensurando os critérios para a elaboração do Índice de Condição da Via. 


\section{Definição de Ferramenta para Avaliação do ICV}

Para definir a ferramenta para avaliação dos segmentos com maior demanda, adaptou-se os critérios utilizados por Dixon (1996) para verificação do Nível de Serviço (ver item 2.2). Neste caso, conforme apresentado na Etapa I, oito indicadores foram definidos para compor o ICV, os quais são descritos como segue:

I. Largura da faixa: tem por objetivo avaliar a segurança e o conforto dos ciclistas em relação à distância dos veículos motorizados a largura das faixas de rolamento por meio da medição em campo ou utilizando um software de SIG. Para efeito de levantamento das dimensões viárias, considera-se a largura efetiva da via a largura total/número de faixas existentes no local; assim como a hierarquia viária e na velocidade média da via apresentado por Brasil (2007) e CBT (1997), consulta-se o quadro 6, como um primeiro parâmetro de indicação do sistema viário a ser utilizado.

Quadro 6 - Propostas de variáveis para análise de espaços para ciclistas.

\begin{tabular}{|c|c|c|c|}
\hline $\begin{array}{l}\text { Vias e trechos nas } \\
\text { cidades }\end{array}$ & $\begin{array}{l}\text { Grau de Restrição } \\
\text { ao uso de ciclovia }\end{array}$ & $\begin{array}{l}\text { Recomendações para o } \\
\text { uso da bicicleta }\end{array}$ & $\begin{array}{c}\text { Velocidade } \\
\text { Máxima conforme } \\
\text { CTB }\end{array}$ \\
\hline Via expressa $\left(1^{a}\right.$ categoria $)$ & Total & Ciclovia Lateral & $>100 \mathrm{~km} / \mathrm{h}$ \\
\hline $\begin{array}{c}\text { Via expressa ( } 2^{\mathrm{a}} \text { e } 3^{\mathrm{a}} \\
\text { categorias) }\end{array}$ & Total & Ciclovia Lateral & $80 \mathrm{~km} / \mathrm{h}$ \\
\hline $\begin{array}{l}\text { Via Arterial }\left(1^{\mathrm{a}} \text { e } 2^{\mathrm{a}}\right. \\
\text { categoria) }\end{array}$ & Parcial & Ciclo faixa & $60 \mathrm{~km} / \mathrm{h}$ \\
\hline Túneis & Total & Ciclovia Lateral & Variável \\
\hline $\begin{array}{c}\text { Viadutos, pontes e } \\
\text { elevados }\end{array}$ & Parcial & $\begin{array}{l}\text { Ciclovia ou Ciclofaixa } \\
\text { (segregação) }\end{array}$ & Variável \\
\hline Via coletora & Parcial & $\begin{array}{l}\text { Ciclovias, ciclofaixa ou } \\
\text { tráfego compartilhado }\end{array}$ & $40 \mathrm{~km} / \mathrm{h}$ \\
\hline Via local & Parcial & $\begin{array}{l}\text { Ciclovias, ciclofaixa ou } \\
\text { tráfego compartilhado }\end{array}$ & $30 \mathrm{~km} / \mathrm{h}$ \\
\hline
\end{tabular}

Fonte adaptada: Brasil (2007) e Brasil (1997). 
Desta forma é possível analisar a largura referencial para cada tipo de sistema cicloviário a ser implantado, conforme análise comparativa com os manuais AASHTO (1999), Geipot (2001), Brasil (2007), e Sustrans (2014).

A largura mínima efetiva mais favorável deve ter no mínimo 4,20 m na faixa junto ao meio-fio para vias compartilhadas, conforme apresentada pelo (DNIT, 2010). As vias urbanas, de acordo com o TRB (2010), têm largura aceitável de 3,00 m.

Caso a largura total da via apresente valores superiores a $4,20 \mathrm{~m}$, pode-se adotar outro tipo de infraestrutura (ciclofaixa ou ciclovia). A medida mínima para ciclofaixas é de 1,80 m e para ciclovias é de 2,0 m segundo parâmetros adotados na Holanda e na França (BRASIL, 2007).

Diante disto, pode-se estabelecer as larguras mínimas efetivas para cada tipo de infraestrutura: via compartilhada $(4,20 \mathrm{~m})$, ciclofaixa $(4,80 \mathrm{~m})$ e ciclovia (5,00m). Assim, pode-se estabelecer as larguras mínimas efetivas para cada tipo de infraestrutura, logo, situações de apinhamento, onde aumentam o risco de acidentes devido à largura insuficiente da via, tiveram valores equivalentes.

II. Velocidade: esse foi calculado por meio da diferença entre a velocidade média do ciclista 15km/h (BRASIL, 2007) e a velocidade máxima permitida aos automóveis. Quanto maior a diferença entre as velocidades dos veículos e dos ciclistas, maior é o risco de acidente (DIXON, 1996; SUSTRAN, 2014), face a ausência da indicação local (placa), usou-se como referência os dados apresentados pelo DNIT (2010).

III. Pavimentação: este fator verifica as condições de manutenção da superfície da via, incluindo os problemas construtivos que resultam em problemas de manutenção, como buracos e rachaduras. Não estão incluídos neste fator os problemas de manutenção de redes (concessionárias) ou acúmulo temporário de matérias, como folhas, etc.

IV. Nível de serviço para veículos/fluxo de veículos: o Nível de Serviço para os veículos motorizados afeta o Nível de Serviço para bicicletas, pois o 
volume de veículos motorizados e o congestionamento influenciam no conforto e na segurança dos ciclistas que trafegam por uma via. O modelo considera que independentemente do NS da via, a presença de um grande número de faixas de tráfego desestimula o ciclista. Logo, adotou-se a referência de baixo fluxo para vias com uma faixa de rolamento, médio fluxo para vias com duas faixas de rolamento e acima de três faixas, alto fluxo.

V. Amenidades: neste item avalia-se a presença de arborização para amenizar o calor e proporcionar maior conforto térmico. Além disso, foi verificada a iluminação do local para proporcionar segurança ao ciclista.

VI. Topografia: esse fator auxilia a mensuração do efeito que a presença de grandes aclives ao longo das vias tem sobre o ciclista. Os parâmetros sugeridos sempre relacionam a declividade em função do comprimento da rampa. Categorizou-se a topografia em três critérios: desejável, aceitável e indesejável (Figura 5) apresentado pelo Manual Americano ABCD's of Bikeways (USA,1979), considerando a estrutura existente no local.

Figura 5 - Relação entre a inclinação da via e a distância máxima.

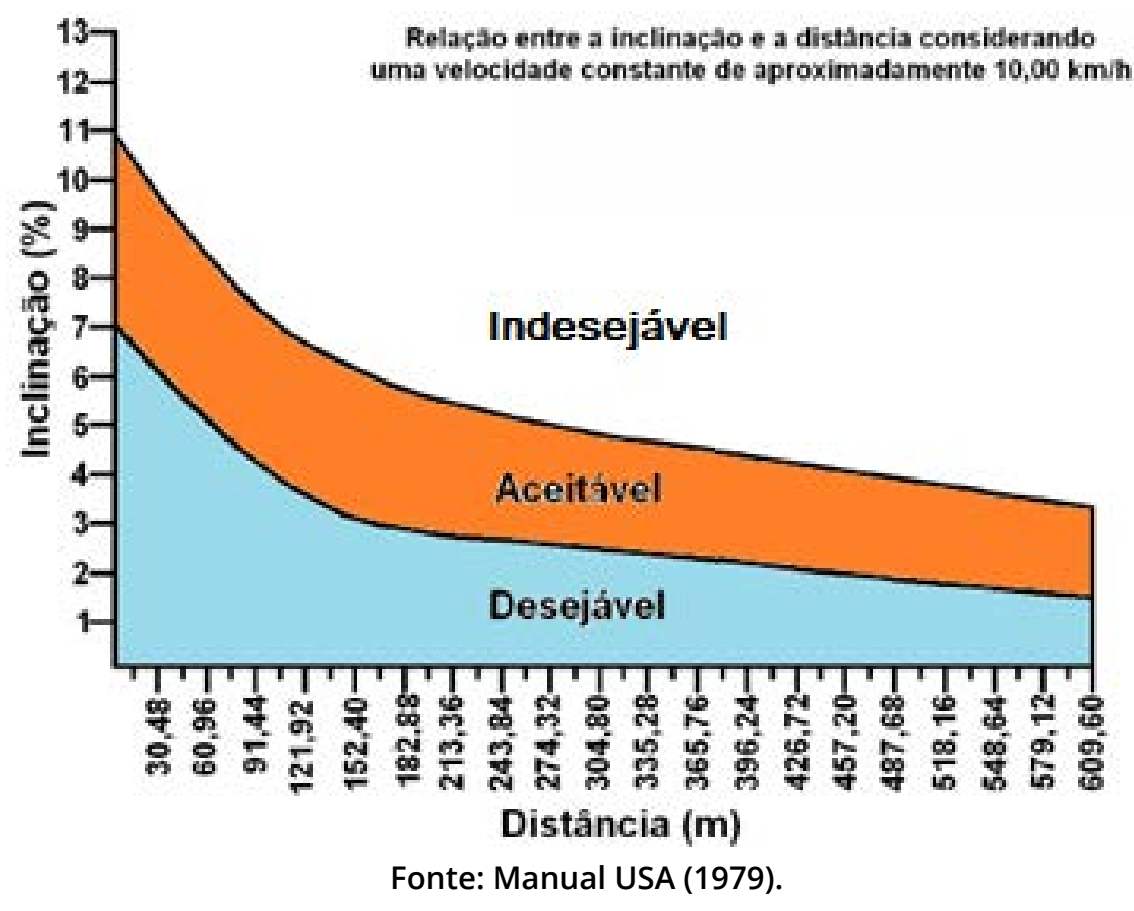


Portanto, caso não seja possível fazer tal suavização de perfil viário em projeto, é recomendável procurar alternativas de rotas, ou a suavização da subida com patamares intermediários retilíneos para descanso (GEIPOT, 2001). Para situações de declive considera-se a pontuação mais favorável.

VII. Sinalização: a presença de sinalização, tanto vertical como horizontal, é fundamental para a prevenção de acidentes. Nos casos com sinalização vertical e horizontal foi atribuída pontuação máxima, a ausência de ambas recebeu baixa pontuação.

VIII. Conflito: esta variável avalia a facilidade de visão entre ciclistas e motoristas de forma a evitar acidentes nas seguintes situações:

a) Ausências de estacionamento na lateral: pode desencorajar o uso deste corredor pelos ciclistas, pois a abertura da porta e circulação de pessoas ao sair dos veículos pode criar problemas de segurança.

b) Ausências de entradas de garagens e cruzamentos: as conversões de garagens e cruzamentos de vias não semaforizadas podem trazer riscos aos ciclistas. Na via que apresentar um número de entradas ou cruzamentos maior que 22 inserções por $1,6 \mathrm{~km}$ o segmento inteiro deixa de ser pontuado, critério estabelecido conforme Dixon (1996).

c) Ausências de barreiras: são consideradas barreiras os elementos físicos ou operacionais (elementos de drenagem, parada de ônibus, interseções com grande número de conversões à direita) que provocam descontinuidade da facilidade para bicicletas, forçando o ciclista a invadir a via ou calçadas em algum trecho específico.

Para uma avaliação eficiente das rotas é necessário que os segmentos sejam divididos em quantos trechos forem necessários, mediante a homogeneidade de suas características físicas como: largura, topografia, morfologia e velocidade da via. O Quadro 7 apresenta as variáveis usadas para avaliar o ICV. 
Quadro 7- Quadro para avaliação do Índice de Condição da Via.

\begin{tabular}{|c|c|c|c|}
\hline Variáveis/indicadores & Critérios & Referenciais & Peso \\
\hline \multirow{3}{*}{ Largura efetiva mínima } & Vias compartilhadas & $\begin{array}{l}<4,20 \\
\geq 4,20\end{array}$ & $\begin{array}{l}0 \\
1\end{array}$ \\
\hline & Ciclofaixas & $\begin{array}{l}<4,80 \\
\geq 4,80\end{array}$ & $\begin{array}{l}0 \\
1\end{array}$ \\
\hline & Ciclovias & $\begin{array}{l}<5,00 \\
\geq 5,00\end{array}$ & $\begin{array}{l}0 \\
1\end{array}$ \\
\hline $\begin{array}{l}\text { Diferencial de velocidade } \\
\text { entre veículos e bicicleta }\end{array}$ & \multicolumn{2}{|c|}{$\begin{array}{c}>48 \mathrm{~km} / \mathrm{h} \\
32 \mathrm{a} 48 \mathrm{Km} / \mathrm{h} \\
24 \text { a } 32 \mathrm{Km} / \mathrm{h}(\text { Dixon,1996) }\end{array}$} & $\begin{array}{c}0,5 \\
1\end{array}$ \\
\hline Conflitos & \multicolumn{2}{|c|}{$\begin{array}{c}\text { Ausência de estacionamento nas laterais } \\
\text { Ausências de entradas de garagens e cruzamentos } \\
\text { Ausências de barreiras }\end{array}$} & $\begin{array}{l}0,33 \\
0,33 \\
0,33\end{array}$ \\
\hline Manutenção das vias & \multicolumn{2}{|c|}{$\begin{array}{l}\text { Problemas graves ou frequentes } \\
\text { Problemas pequenos ou ocasionais } \\
\text { Sem problemas }\end{array}$} & $\begin{array}{c}0 \\
0,5 \\
1\end{array}$ \\
\hline Fluxo de Veículos & \multicolumn{2}{|c|}{$\begin{array}{l}\text { Alto fluxo - mais de } 3 \text { faixas rolamento } \\
\text { Médio Fluxo - entre } 2 \text { e } 3 \text { faixas rolamento } \\
\text { Baixo fluxo - uma faixa rolamento }\end{array}$} & $\begin{array}{c}0 \\
1 \\
0,5\end{array}$ \\
\hline Amenidades & \multicolumn{2}{|c|}{$\begin{array}{c}\text { Iluminação } \\
\text { Arborização - sombra durante parte do dia }\end{array}$} & $\begin{array}{l}0,5 \\
0,5\end{array}$ \\
\hline Topografia (Aclive) & \multicolumn{2}{|c|}{$\begin{array}{l}\text { Indesejável } \\
\text { Aceitável } \\
\text { Desejável }\end{array}$} & $\begin{array}{c}0 \\
0,5 \\
1\end{array}$ \\
\hline Sinalização & \multicolumn{2}{|c|}{$\begin{array}{c}\text { Inexistente } \\
\text { Existente (vertical e/ou horizontal) }\end{array}$} & $\begin{array}{l}0 \\
1\end{array}$ \\
\hline \multicolumn{3}{|c|}{$\begin{array}{l}\text { Valor total (categorias) } \\
\text { tos = soma dos pontos na } \\
\text { ttos = soma dos pontos na } \\
\text { nprimento no segmento/co } \\
\text { tados = Índice dos segme } \\
\text { dos Índices Ajustados dos }\end{array}$} & 1,00 \\
\hline
\end{tabular}

Fonte: os autores (2020).

Cada segmento analisado recebe uma nota que pode chegar até 1,0, o qual é considerado o segmento com maior necessidade e condições de melhoramentos. Propõe-se aplicar um processo de normatização análogo ao proposto por Eastman e Jiang (2010) em que classifica os segmentos em A, B ou C. Nesta escala se o valor apurado do índice para o segmento estiver entre 0 até 0,33 é considerado ruim. De 0,33 até 0,67 , o segmento apresenta uma boa situação. Quando o resultado apresentar valor superior a 0,68, tem-se uma situação muito boa (ver Quadro 8). 
Quadro 8 - - Classificação dos segmentos viários.

\begin{tabular}{|c|c|c|}
\hline Índice & Classificação & Característica do segmento \\
\hline 0 a 0,33 & C-ruim & $\begin{array}{r}\text { Segmento ruim, não aconselhado, trecho necessita de grandes } \\
\text { intervenções ou modificações. }\end{array}$ \\
\hline 0,34 a 0,67 & B-boa & $\begin{array}{r}\text { Segmento bom, cujo uso dentro do sistema cicloviário é } \\
\text { aconselhado, podendo ser realizado intervenções nos indicadores } \\
\text { com baixa avaliação. }\end{array}$ \\
\hline 0,68 a 1,00 & A-Muito boa & $\begin{array}{r}\text { Segmento ótimo, necessitando de pequenas ou nenhuma } \\
\text { intervenções nos segmentos que tiveram um menor resultado. }\end{array}$ \\
\hline
\end{tabular}

Fonte: os autores (2020).

\section{Conclusão}

A política de mobilidade urbana em vigência na maioria das cidades brasileiras foi orientada pelo e para o transporte motorizado individual, modelo este que trás sinais de esgotamento em face aos constantes congestionamentos e problemas que se apresentam nas cidades. Os problemas urbanos causados pelo planejamento de transporte que prioriza o uso do automóvel em detrimento de outros meios de transporte indicam a bicicleta como uma alternativa viável e sustentável de transporte urbano nas cidades brasileiras. No entanto, boa parte da frota brasileira de bicicletas não circula, principalmente pela falta de segurança do ciclista nas cidades, e pela falta de políticas públicas voltadas a esse tipo de transporte.

Neste sentido, este trabalho contribuiu com o desenvolvimento de uma ferramenta que colabora para o planejamento e avaliação de sistemas cicloviários, visando ações efetivas de fomento ao uso da bicicleta, sem que sejam onerosas ao poder público e que sejam atrativas aos usuários, integrando os requisitos técnicos da implantação do sistema cicloviário com a perspectiva comportamental do usuário, apresentado pela Psicologia Ambiental. Assim, desenvolveu-se um índice de fácil aplicação por englobar indicadores que auxiliam no processo de decisão, além de permitir a identificação de uma rota ou trecho mais eficiente de forma a facilitar a implementação de infraestruturas cicloviárias. 
Ressalta-se que a escolha dos indicadores foi baseada nos parâmetros e critérios dos métodos de avaliação dos níveis de serviço de ciclovias (foco comportamental), assim como na relação que se estabelece nos critérios da Psicologia Ambiental apresentados por Hamer e Almeida (2016b), em que prevaleceram oito critérios integrados no quadro 6 de análise do Índice de Condição da Via (ICV).

Segundo Delabrida (2004), o fenômeno do transporte e da mobilidade é uma somatória dos comportamentos dos indivíduos nos contextos urbanos; sendo uma área ainda pouco pesquisada pela psicologia, reconhecendo a natureza multidisciplinar da questão. O caminho da interdisciplinaridade percorridos nesta pesquisa buscou compreender a dinâmica que se estabelece entre o indivíduo e o ambiente físico, e com isso, compreender o indivíduo no meio de transporte e também a dinâmica que se estabelece desta relação, proporcionando uma nova visão do ambiente urbano sob um novo olhar na busca de ambientes mais atrativos.

Como sugestões para futuros trabalhos a serem desenvolvidos sobre o tema, têm-se:

- Análise da influência do número de postos de trabalho e/ou estudo nas áreas de influência;

- Identificar características socioeconômicas para definição de padrões de uso do solo eficientes para implantação de ciclovias;

- Aplicação do Método de Análise Hierárquica em outras cidades, onde poderão ser identificados outros indicadores e prioridades. 


\section{REFERÊNCIAS}

AASHATO. Guide for the Development of Bicycle Facilities, American Association of State Highway and Transportation Officials. Washington, D.C. USA, 1999. Disponível em: https://nacto.org/wp-content/ uploads/2011/03/AASHTO-Guide-for-the-Development-of-Bicycle-Facilities-1999.pdf. Acesso em: 12 dez. 2016.

ALTMAN, I. Environment and Social Behaviour: Privacity, personal space, territory and crowding. Monterre, CA: Brooks/Cole. 1975, 256 p.

ANTP - Associação Nacional de Transporte Público. Sistema de Informações de Mobilidade, Relatório Geral de 2016. Publicado em maio. 2018. Disponível: http://files.antp.org.br/simob/simob2016-v6.pdf . Acesso em: 03 janeiro, 2020.

BRASIL. Lei n. 9.503, 23 de setembro de 1997. CTB - Código de Trânsito Brasileiro. Diário Oficial da União, Brasília-DF, 1997. Disponível em: http://www.planalto.gov.br/ccivil_03/leis/L9503.htm. Acesso: 08 junho, 2017.

BRASIL. Secretaria Nacional de Transportes e da Mobilidade Urbana. Caderno de Referência para a Elaboração de Plano de Mobilidade por Bicicleta nas Cidades - Ministério das Cidades, Secretaria Nacional de Transporte e da Mobilidade Urbana, 2007. 232 p.

BRASIL. Lei n 12.587, de 03 de janeiro de 2012. Lei Federal de Mobilidade Urbana. Diário Oficial da União, Brasília-DF, 2012. Disponível em: http://www.planalto.gov.br/ccivil_03/_ato2011-2014/2012/lei/ 112587.htm. Acesso: 26 julho, 2016.

BELL et. al. Environmental Perception and Cognition In: Bell, P. A. et al. (1996) Environmental Psychology. 5.ed. Fort Worth, TX: Harcourt College Publishers.

COSTA, H. G. Introdução ao método de análise hierárquica: Análise multicritério no auxílio à decisão. XXXVI - SBPO, O Impacto da Pesquisa Operacional nas Novas Tendências Multidisciplinares. $1^{\text {a }}$ Edição. Niterói, RJ. 2002. p.83-85.

DAVIS, J. Bicycle Safety Evaluation. Auburn University, Auburn City of Chattanooga, and ChattanoogaHamilton County Regional Planning Commission, Chattanooga, June 1987.

DAVIS, G. A.; WICKLATZ, Trina. Sample-Based Estimation of Bicycle Miles of Travel (BMT). Retrieved from the University of Minnesota Digital Conservancy, 2001. Disponível em: http://hdl.handle. net/11299/742.

DELABRIDA, Z. N. C. A imagem do Uso da Bicicleta: Um estudo entre moradores de Taguatinga. Dissertação de Mestrado. Instituto de Psicologia. Universidade de Brasília, Brasília, DF, 2004, 77p. 
DIXON, L. B. Bicycle and Pedestrian Level-of-Service Performance Measures and Standards for Congestion Management Systems. Transportation Research Record n.1538, 1996. p. 1- 9.

DNIT - Departamento Nacional de Infraestrutura de Transportes. Manual de Projetos Geométricos para Travessias Urbanas. Rio de Janeiro - RJ, Brasil, 2010, 392 p.

EASTMAN, R.; JIANG, H. Fuzzy. Measures in Multicriteria Evaluation. Application of fuzzy measures in multi-criteria evaluation in GIS, International Journal of Geographical Information Science, 2010, 14:2, 173-184, DOI: 10.1080/136588100240903

EPPERSON, B. Evaluating Suitability of Roadways for Bicycle Use: toward a cycling level of service standart. Transportation Research Record. Washington, DC, United States, 1994. Disponível em: http:// onlinepubs.trb.org/Onlinepubs/trr/1994/1438/1438-002.pdf. Acesso: 15 junho, 2016.

EVERETT, P. B. e WATSON, B. G. Psychological Contributions to Transportation. Em D. Stokols \& I. Altman (Eds.), Handbook of environmental psychology, vol II (pp. 987-1008). New York: Wiley. DC. 1987.

FISHER et. al. Envirohnmental Psychology, $2^{\mathrm{a}}$ edição. Nova Yorque, Holt, Rinehart and Winston, 1984.

FHWA - Federal Highway Administration. Guide on Methods to Estimate Non - Motorized Demand Travel. Suporting Documentation. Washington, D.C. USA. July, 1999.

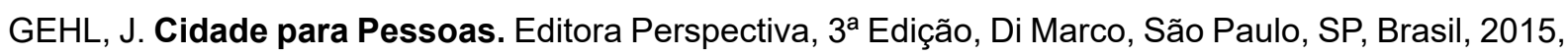
$280 \mathrm{p}$.

GEIPOT - Grupo Executivo de Integração da Política de Transporte. Planejamento Cicloviário: Diagnóstico Nacional. Brasília, DF. 2001. Disponível em: https://drive.google.com/file/d/0BxR5Ri6g5X_ ZTXVWS3pyVUdPdDA/view. Acesso: 03 maio de 2015.

GIFFORD, R. Environmental Psichology: Principles and Practical ( $2^{\mathrm{a}}$ ed.) Boston, MA: Allyn e Bacon, $1987,506 \mathrm{p}$.

GUNTHER, H. Mobilidade e "affordance" como cerne dos Estudos Pessoa-Ambiente. Estudos de Psicologia, 8(2).273-280. 2003. UnB. Brasília, DF. DOI: https://dx.doi.org/10.1590/S1413294X2003000200009

HALL. E. T. The hidden dimension, New York, Doubleday, 1966. Disponível em: www.philo-online. com/TEXTES/HALL Edward Twichell - The hidden dimension.pdf. Acesso em: 10 janeiro, 2017.

HAMER, L. J. Metodologia para Implantação e Avaliação de Sistemas Cicloviários sob o Enfoque da Psicologia Ambiental. Dissertação (Mestrado) - Universidade Federal de Goiás, Faculdade de Artes Visuais (FAV), Programa de Pós-Graduação em Arquitetura - Projeto e Cidade, Goiânia, 2017. 
HAMER, L.J., ALMEIDA C.F. Variáveis Psicológicas e o Nível de Serviço que Predizem a Mobilidade Urbana na Implantação de Ciclovias. VII Congresso Luso Brasileiro para o Planejamento Urbano, Regional, Integrado e Sustentável PLURIS 2016. Maceió, AL. Disponível em: https://fau.ufal.br/ evento/pluris2016/files/Tema\%203\%20-\%20Mobilidade\%20e\%20Transportes/Paper1133.pdf

HAMER, L.J.; ALMEIDA C.F.; ANDRADE, K. Contribuição para definição de diretrizes para Implantação de ciclovias com base na identificação do perfil do Usuário potencial de bicicletas: Um estudo no Corredor Universitário de Goiânia. XXIX Congresso de Pesquisa e Ensino de Transporte. Ouro Preto, MG, 2016b.

HAMER, L.J.; ALMEIDA C.F. Variáveis Psicológicas e o Nível de Serviço que Predizem a Mobilidade Urbana na Implantação de Ciclovias. VII Congresso Luso Brasileiro para o Planejamento Urbano, Regional, Integrado e Sustentável PLURIS 2016c. Maceió, CE.

HCM - Highway Capacity Manual. Transportation Research Board. Washington, D.C., EUA: National Research Council, 2000.

HEIMSTRA, N.W.; McFARLING L.H. Psicologia Ambiental. Tradução de Manoel Andrade Schmidt, São Paulo: EPU: Ed. da Universidade de São Paulo, SP. 1978.

HUNTER et. al. Bicycle-motor vehicle crash types: the early. Transportation Research Record 1502,1999 p. $68-74$.

LANDIS et. al. Real time human perceptions: toward a bicycle level of service. Transportation Record. Washington D.C. January, 1997. DOI: 10.3141/1578-15

LEE, T. Psicologia e meio ambiente. Rio de Janeiro: Zahar. 1977.

LEWIN, K. Forças Ambientais no Comportamento e Desenvolvimento Infantil. In K.Lewin, Teoria dinâmica da personalidade (pp.71-115) Ed. Cutrix São Paulo, SP, Brasil, 1975.

LYNCH, K. A imagem da cidade. Editora Martins Fontes, Coleção Mundo da Arte, São Paulo, SP. 1997, 240 p.

KIRNER, J. Proposta de um método para a Definição de Rotas Cicláveis em Areas Urbanas, Dissertação (Mestrado) - Universidade Federal de São Carlos , São Carlos, SP, Brasil, 2006, $110 f$.

KOHLSDORF, M.E. A Apreensão da Forma da Cidade. Editora UnB, Brasília, DF. 1996. 240 p.MORVAL, J. Psicologia Ambiental. Coleção Epigénese, desenvolvimento e psicologia; Tradução de António Viegas. Instituto Piaget. Lisboa, Portugal, 2007. 138 p.

MOSER, G. Psicologia ambiental. Estudos de Psicologia, 3(1), 1998. p. 121-130. 
MONTEIRO, F.B.; CAMPOS, V. B. G. Métodos de Avaliação da Qualidade dos Espaços para Ciclistas. Anais do XXV Congresso da ANPET, Belo Horizonte, MG. v2, pp.1242-1253, 2011.

MORVAL, J. Psicologia Ambiental. Coleção Epigénese, desenvolvimento e psicologia; Tradução de António Viegas. Instituto Piaget. Lisboa, Portugal, 2007.

PAIVA, M. Fatores que Influenciam no Uso da Bicicleta de Forma Integrada com o Metrô. Tese de doutorado em Transportes, Publicação T. D - 002A/2013, Departamento de Engenharia Civil e Ambiental, UnB, Brasília, DF, 2013. 206 p.

PEZZUTO, C. C. Fatores que influenciam o uso da bicicleta. Dissertação de Mestrado em Engenharia Urbana - centro de Ciências Exatas, Universidade São Carlos, São Carlos, SP, 2002.

RAMOS, P.A.M. Projecto de Ciclovias. Dissertação de Mestrado, Escola de Engenharia Civil Departamento de Transportes, Universidade de Porto. Lisboa, Portugal, 2008.

SAATY, T.L. The Analytic Hierarqchy Process. Tradução e revisão por Wainer da Silveira e Silva, McGraw-Hill, Makron, São Paulo, SP, Brasil, 1991. pp. 278.

SAATY, T.L. Decision Making with Dependence and Feedback: The Analytic Network Process, RWS Publications, Pittsburgh, PA, USA. 2001.

SOARES, U.P. Procedimento para a Localização de Terminais Rodoviários Interurbanos, Interestaduais de Passageiros. Dissertação em Engenharia de Transporte . COOPPE/UFG, Rio de Janeiro, RJ, Brasil, 2006.

SOCKZA, L. Contextos Humanos e Psicologia Ambiental. Fundação Calouste Gulbenkian. Lisboa, Portugal, 2005.

SOMMER, R. Personal Space. Englewood Cliffs: Prentice-Hall, 1969.

SORTON, A.; WALSH, T. Bicycle stress level as a tool to evaluate urban and suburban bicycle compatibility. Transportation Research Record, n 1438, 1994. pp. 17-24.

STOKOLS, D. Bridging the theoretical and applied facets of Environmental Psychology. American Psychologist, Ed.51a, 1188- 1189. November, 1996. DOI: 10.1037/0003-066X.51.11.1188.

SUSTRANS. The national Cycle Network: Guide and Pratical Details issue 2, Bristol, UK, 1997. Disponível em/; <http: sustrans .org.uk/resoures/technical-guidelines>. Acesso em: 15 Julho 2016.

SUSTRANS. Design Manual Handbook for Cycle-friendly Design. Bristol, UK, 2014. Dispomível em: <http://www.sustrans.org.uk/sites/default/files/file_content_type/sustrans_handbook_for_cyclefriendly_design_11_04_14.pdf. Acesso em 19/03/2017. 
TRB - TRANSPORTATION RESEARCH BOARD. Highway Capacity Manual. Washington, D.C., EUA: National Research Council. 2000.

TREVIZANO, W. A.; FREITAS, A. L. P. Emprego do Método de Análise Hierárquica (MAH) na seleção de processadores. In:XXV Encontro Nacional de Engenharia de Produção - Porto Alegre, RS, Brasil, 2005.

TUAN, Yi-F. Espaço e lugar: a perspectiva da experiência. São Paulo: Difel, 1983.

USA- UNITED STATES OF AMERICA. Departamento of Transportation. Federal Highway Administration. The ABC's of Bikeways. Washington, DC. 1979. Disponivel em: <http:www.lume.ufrg.br/bitstream/ handle/10183/28577/000769157.pdf?sequence=1>. Acesso em: 13/03/2017.

VILAÇA, L. B. Comportamento sócio-espacial de pessoas em movimento: um estudo exploratório no calçadão da Avenida Engenheiro Roberto Freire. 2008. 188 f. Dissertação (Mestrado em Psicologia, Sociedade e Qualidade de Vida) - Universidade Federal do Rio Grande do Norte, Natal, 2008.

\section{Publisher}

Universidade Federal de Goiás. Faculdade/Instituto/Escola. Programa de Pós-graduação Projeto e Cidade. Publicação no Portal de Periódicos UFG.

As ideias expressadas neste artigo são de responsabilidade de seus autores, não representando, necessariamente, a opinião dos editores ou da universidade.

RECEBIDO EM: 16/12/2020

APROVADO EM: $18 / 12 / 2020$

PUBLICADO EM: 28/12/2020 